\title{
Patient perceptions of allied health student communication and interpersonal skills: A cross-sectional study
}

\author{
N. Tripodi1, 2, 3,4, S. Cossar³, J. Davidson³ , R. Farmer ${ }^{3}$, J. Gorbonos$^{3}$, \\ A. McDonald ${ }^{3} \&$ M. Pierlot ${ }^{3}$
}

\begin{abstract}
Introduction: Effective patient-practitioner communication contributes to patient health outcomes by strengthening therapeutic relationships and, in the process, contributing to overall quality of patient care. Despite the growth of student-led university teaching clinics, little research has investigated communication skills within this context. Therefore, the aim of this study was to investigate the patient-perceived levels of communication and interpersonal skills within a student-led allied health clinic.
\end{abstract}

Methods: The Communication Assessment Tool (CAT) was used to collect crosssectional data on patients' perceptions of student communication and interpersonal skills within an osteopathy teaching clinic. Data were analysed via descriptive and inferential statistics.

Results: According to the CAT, patients perceived the students' communication and interpersonal skills to be "excellent" overall (97.2\%). No significant differences were found between percentage of "excellent" responses and gender $(p=.600)$, number of consultations $(p=.374)$ or pain duration $(p=.741)$.

Conclusions: Patients in this setting perceive student communication and interpersonal skills to be of a high standard. This can contribute positively to the patient-practitioner therapeutic alliance and may improve overall health outcomes. These findings have

\footnotetext{
Institute of Health and Sport, Victoria University, Melbourne, Australia

First Year College, Victoria University, Melbourne, Australia

Osteopathy Group, College of Health and Biomedicine, Victoria University, Melbourne, Australia

4 Australian Institute for Musculoskeletal Science (AIMSS), University of Melbourne and Western Health, St Albans,

Melbourne, VIC, Australia
}

\section{Correspondence}

Nicholas Tripodi

301 Flinders Lane

Melbourne, VIC 3000

Australia

Tel: +61399191603

Email: nicholas.tripodi@vu.edu.au 
implications for communication training within student-led health professions clinics and tertiary curricula more broadly.

Keywords: practitioner communication; allied health education; communication assessment tool; communication skills; health outcomes

\section{Introduction}

Communication can be defined as a two-way process or exchange of thoughts, information and feelings, using speech, body language and other methods (Kourkouta \& Papathanasiou, 2014). In healthcare, poor communication often leads to discontinuity of care and patient dissatisfaction (Vermeir et al., 2015). In fact, the majority of patient complaints arise secondary to a breakdown in communication between the patient and practitioner (O'Keeffe et al., 2016). Within the allied health setting, communication and interpersonal skills are an important element of clinical practice and can have a strong influence on the patient experience (Thomson \& Collyer, 2017; Vaughan et al., 2019). Communication skills are of high importance to patients, with preferences favouring practitioners who involve the patient in decision making and demonstrate empathy (Leach et al., 2013). Effective patient-practitioner communication and interpersonal skills may, therefore, enhance the therapeutic alliance and, in turn, patient satisfaction (O'Keeffe et al., 2016; Pinto et al., 2012; Street et al., 2009; Thomson \& Collyer, 2017). However, it is important to note that there is often a disconnect between how practitioners and patients perceive practitioner communication and empathy skills (Hojat et al., 2017), hence the need to intentionally seek patient-centred evaluation of clinician communication skills.

Research by Thomson and Collyer (2017) reveals that the language used by practitioners influences patient beliefs and engagement levels. Specifically, using metaphors and analogies, and reassuring patients, lead to them taking a more active role in their healthcare management, which can positively impact patient health outcomes overall (Thomson \& Collyer, 2017). These findings emphasise the influential role practitioners have and the importance of critically analysing communication styles used with patients to better convey trust, empathy and respect. Despite this role, good patient communication skills are not necessarily innate, and hence, many health professions curricula emphasise communication as a core competency. To promote effective communication, a patient-centred approach is imperative. This involves the clinician and patient working together on a management plan that is achievable and that considers the patient's preferences and past experiences (Pinto et al., 2012). Research has found that relationship-centred communication training, such as video or small group skills demonstrations, ultimately improves both patient and practitioner satisfaction (Boissy et al., 2016). Within allied health education, a combined approach using structured training, modelling and problem-based learning can be adopted to foster communication skills in order to optimise patient outcomes and satisfaction (Muddle et al., 2019). 
Developed by Makoul et al. (2007), the Communication Assessment Tool (CAT) is a validated patient reported experience measure (PREM) that subjectively evaluates the patient's perceptions of how well a health professional achieves key interpersonal and communication tasks within a single consultation. Examples of these communication skills include speaking in terms patients can understand and encouraging patients to ask questions. The CAT is applicable to a variety of clinical settings and specialties, such as paediatrics, general surgery, family medicine and psychiatry (DeBlasio et al., 2019; Makoul et al., 2007; Myerholtz et al., 2010; Pestana-Santos et al., 2018; Stausmire et al., 2015; Yu et al., 2018). Most PREMs assess the practitioner on their communication with a single question or evaluate the practitioner's communication skills in conjunction with other clinical competencies, limiting the reliability of these measures (Myerholtz et al., 2010). The CAT is unique, as it asks patients to assess practitioners immediately after a consultation, with all the components of interpersonal communication individually rated, potentially overcoming the limitations of other PREMs (Myerholtz et al., 2010; Stausmire et al., 2015). Another advantage of the CAT is that the data collected can provide health professionals with immediate feedback regarding their communication skills and the patient's experience. Clinicians, students or educators can then use these results as a feedback tool to improve their patient communication skills, thereby completing the feedback loop (Kingsley \& Patel, 2017).

Osteopaths are allied health professionals who predominately examine, diagnose and manage musculoskeletal pain and injury. In Australia, osteopaths complete a double degree at a public university. Although musculoskeletal examination and management account for a large part of the curriculum, communication and interpersonal skills are considered a core capability of osteopathic practice and are, therefore, a strong curricular focus. Despite the recent growth in student-led allied health clinics at public universities, detailed investigations into the patient's perceptions of practitioner communication in this setting are currently lacking (Carrigan et al., 2001), and specifically, there has been scant work of this nature performed in an osteopathic setting. To this end, we sought to establish data concerning these perceptions within a university osteopathic teaching clinic in Melbourne, Australia. The aim of this study was to investigate and quantify the patient perceived levels of practitioner communication and interpersonal skills. The data obtained from this project will not only provide insight into the competency of patient-practitioner communication but will also inform current and future allied health education curricula.

\section{Methods}

\section{Ethical approval}

Ethical approval to conduct this study was obtained from the Victoria University (VU) Human Research Ethics Committee (Approval Number: HRE 19-124). 


\section{Study design, participants and sample size}

This study employed an observational, quantitative cross-sectional design. The participants were obtained via a convenience sample of patients attending the VU osteopathy student clinics. The study sample included both new and return patients. Participants were excluded if they were under the age of 18 or had a cognitive impairment, intellectual disability or mental illness and were unable to provide informed consent.

The participants were recruited by inviting patients, at the reception desk, to complete the questionnaire following a consultation. Clinical data from VU illustrated that there are approximately 8,000 patient visits to the student clinic over the course of 12 months. With a $95 \%$ confidence interval and a $5 \%$ margin of error, the ideal sample size for this study was calculated at 367 participants for a 12 -month period. This figure was adjusted for a 3.5-month data collection period, and a target number of 107 was defined. To reduce selection bias, participants who completed the survey remained anonymous to their treating student practitioners, and researchers were blinded to the identity of the participants of the study.

\section{Setting}

The study was based at the VU student osteopathic teaching clinics in Melbourne, Victoria, Australia. As part of the Master of Health Science (Osteopathy) degree, students are required to engage in placement at university-run student clinics. The clinics are community-based and set up as teaching clinics, with students as treating practitioners, supervised by qualified osteopaths. Students are required to complete a minimum of 350 placement hours over 18 months in order to meet the requirements of their degree. Supervising clinicians are qualified osteopaths who are currently registered as treating practitioners through the Australian Health Practitioner Regulation Agency (AHPRA). In Australia, osteopaths are governed by AHPRA to ensure practitioners are practising within their scope. This scope of practice has been set by AHPRA and defines Australian osteopaths as primary healthcare practitioners. Their scope encompasses primary assessment, the application of manual therapies, education and health promotion tailored to patients (Osteopathy Australia, 2018). The role of the clinician is to oversee students to ensure they are examining and treating patients in a safe and effective manner and to advise and guide students on communication, manual examination and technique, and exercise rehabilitation skills. They also facilitate extra tutorials to further enhance the students' knowledge.

\section{Data collection tools}

Data was collected using the CAT. The CAT contains 15 items related to practitioner communication and interpersonal skills, rated on a 5-point patient Likert scale, with responses ranging from "poor" to "excellent" (Makoul et al., 2007). This tool is designed to analyse the patient perceptions of practitioner communication and interpersonal skills (Table 1) (Makoul et al., 2007). The CAT has been shown to have overall high 
reliability with a Cronbach's alpha of 0.96 and high levels of internal consistency (Makoul et al., 2007). Supplementary demographic questions were added to investigate further correlations and potential influencing factors on patient experience, as used by DeBlasio et al. (2019). The additions included questions regarding patients' age, gender, pain duration and region of complaint.

\section{Table 1}

Means, Percentage and Standard Deviation (SD) of CAT Responses

\begin{tabular}{|c|c|c|c|c|c|c|c|}
\hline CAT Questions & 1:Poor & 2: Fair & 3: Good & 4: Very Good & 5:Excellent & $\begin{array}{c}\text { Mean } \\
\text { Response }\end{array}$ & $\operatorname{SD}(1 \sigma)$ \\
\hline $\begin{array}{l}\text { 01: Greeted me in a } \\
\text { way that made me } \\
\text { feel comfortable }\end{array}$ & $0 \%$ & $0 \%$ & $0 \%$ & $8.5 \%$ & $91.5 \%$ & 4.92 & 0.28 \\
\hline $\begin{array}{l}\text { 02: Treated me } \\
\text { with respect }\end{array}$ & $0 \%$ & $0 \%$ & $0 \%$ & $8.5 \%$ & $91.5 \%$ & 4.92 & 0.28 \\
\hline $\begin{array}{l}\text { 03: Showed interest } \\
\text { in my ideas about } \\
\text { my health }\end{array}$ & $0 \%$ & $0 \%$ & $0 \%$ & $11.3 \%$ & $88.7 \%$ & 4.89 & 0.32 \\
\hline $\begin{array}{l}\text { Q4: Understood my } \\
\text { main health concerns }\end{array}$ & $0 \%$ & $0 \%$ & $0 \%$ & $12.3 \%$ & $87.7 \%$ & 4.88 & 0.33 \\
\hline $\begin{array}{l}\text { 05: Paid attention } \\
\text { to me }\end{array}$ & $0 \%$ & $0 \%$ & $0 \%$ & $12.4 \%$ & $87.7 \%$ & 4.88 & 0.33 \\
\hline $\begin{array}{l}\text { 06: Let me talk } \\
\text { without interruptions }\end{array}$ & $0 \%$ & $0 \%$ & $1.9 \%$ & $10.4 \%$ & $87.7 \%$ & 4.86 & 0.40 \\
\hline $\begin{array}{l}\text { 07: Gave me as } \\
\text { much information } \\
\text { as I wanted }\end{array}$ & $0 \%$ & $0 \%$ & $.9 \%$ & $7.5 \%$ & $91.5 \%$ & 4.91 & 0.32 \\
\hline $\begin{array}{l}\text { 08: Talked in terms I } \\
\text { could understand }\end{array}$ & $0 \%$ & $0 \%$ & $2.8 \%$ & $11.3 \%$ & $84.9 \%$ & 4.87 & 0.60 \\
\hline $\begin{array}{l}\text { 09: Checked to be } \\
\text { sure I understood } \\
\text { everything }\end{array}$ & $0 \%$ & $0 \%$ & $1.9 \%$ & $17 \%$ & $81.1 \%$ & 4.80 & 0.45 \\
\hline $\begin{array}{l}\text { 010: Encouraged me } \\
\text { to ask questions }\end{array}$ & $0 \%$ & $0 \%$ & $4.7 \%$ & $16 \%$ & $79.2 \%$ & 4.75 & 0.54 \\
\hline $\begin{array}{l}\text { 011: Involved me in } \\
\text { decisions as much } \\
\text { as I wanted }\end{array}$ & $0 \%$ & $0 \%$ & $3.8 \%$ & $10.4 \%$ & $85.8 \%$ & 4.80 & 0.47 \\
\hline $\begin{array}{l}\text { 012: Discussed next } \\
\text { steps, including any } \\
\text { follow-up plans }\end{array}$ & $0 \%$ & $.9 \%$ & $2.8 \%$ & $10.4 \%$ & $85.8 \%$ & 4.81 & 0.52 \\
\hline $\begin{array}{l}\text { 013: Showed care } \\
\text { and concern }\end{array}$ & $0 \%$ & $0 \%$ & $.9 \%$ & $6.6 \%$ & $92.5 \%$ & 4.92 & 0.31 \\
\hline
\end{tabular}




\begin{tabular}{l|c|c|c|c|c|c|c}
\hline CAT Questions & 1:Poor & 2: Fair & 3: Good & 4: Very Good & 5:Excellent & $\begin{array}{c}\text { Mean } \\
\text { Response }\end{array}$ & SD (1- $)$ \\
\hline $\begin{array}{l}\text { Q14: Spent the right } \\
\text { amount of time } \\
\text { with me }\end{array}$ & $0 \%$ & $0 \%$ & $0 \%$ & $8.5 \%$ & $91.5 \%$ & 4.92 & 0.28 \\
\hline $\begin{array}{l}\text { 015: The clinic staff } \\
\text { treated me with } \\
\text { respect }\end{array}$ & $0 \%$ & $0 \%$ & $0 \%$ & $10.4 \%$ & $89.6 \%$ & 4.81 & 0.31 \\
\hline
\end{tabular}

Data collection took place between November 2019 and February 2020. Participants were asked to complete the questionnaire immediately after their treatment at the clinic or later at home. Participants deposited their consent form and questionnaire after completion in a secured locked box at reception to ensure patient confidentiality.

\section{Data analysis}

Quantitative data were entered into Microsoft Excel for analysis (Microsoft, USA) and exported to SPSS Version 25 (IBM, USA), where descriptive statistics were generated for each questionnaire item in the form of percentage of "excellent" responses (Makoul et al., 2007). Cronbach's alpha was used to assess the internal consistency of the questionnaire items, and a Kolmogorov-Smirnov test was used to test for statistical normality. As the data was considered non-parametric $(p<.001)$, a Mann-Whitney $U$ test was used to assess if any significant differences existed between percentage of "excellent" responses and gender, history of osteopathy visits (new or return patient) or two time point pain duration (0-3 months (acute); > 3 months (chronic)) duration. A Kruskal-Wallis test was used to assess if any significant differences existed between percentage of "excellent" responses and four time point pain duration (< 1 month; 1-3 months; 3-6 months; > 12 months) duration. Percentage of "excellent" responses was used as the main outcome variable, as this is how the CAT is scored (Makoul et al., 2007). While this outcome variable has, in past research, been analysed with gender and history of visits (DeBlasio et al., 2019; Myerholtz et al., 2010), we added in two pain duration comparisons (two and four time point duration), as it may have had implications for clinical teaching practices (i.e., using different communication strategies for patients with acute versus chronic pain).

\section{Results}

A total of 111 CAT forms were provided to participants, with 107 forms completed, equating to a $95.4 \%$ response rate. The patient sample included a broad range of patient ages, ranging from 18 to 83 years, with the average being 37.8 years and the median being 31 years. The majority of participants were female (59.4\%), with the remainder $(40.6 \%)$ being male. Of the participants, $6.6 \%$ had completed the CAT at least once before (i.e., in the same clinic with a different practitioner). Most participants presented with pain lasting longer than 6 months (43.4\%), while $23.6 \%$ had pain for less than 1 month, $20.8 \%$ from $1-3$ months and $12.3 \%$ from 3-6 months (Table 2 ). 


\section{Table 2}

Participant Characteristics by Percentage Frequency

\begin{tabular}{l|c}
\hline Participant Characteristics & $\begin{array}{c}\text { Percentage of } \\
\text { Responses }\end{array}$ \\
\hline Gender & \\
\hline Male & 40.6 \\
\hline Female & 59.4 \\
\hline First-time patient & \\
\hline Yes & 30.2 \\
\hline No & 69.8 \\
\hline Completed CAT before & \\
\hline No & 93.4 \\
\hline Yes & 6.6 \\
\hline No. of pain locations & 28.4 \\
\hline 1 & \\
\hline 2 & \\
\hline 3 or more & 26.7 \\
\hline Pain duration & \\
\hline$<1$ month & \\
\hline $1-3$ months & \\
\hline $3-6$ months & \\
\hline 6 months + & \\
\hline
\end{tabular}

Overall, the participants rated the student practitioners' communication skills highly, with all domains scoring at least 79.2\% "excellent" and a mean overall CAT score of 4.86/5. The most "excellent" responses were recorded for the items "showed care and concern" (92.5\%), "greeted me in a way that made me feel comfortable" (91.5\%), "treated me with respect" (91.5\% ), "gave me as much information as I wanted" (91.5\%) and "spent the right amount of time with me" (91.5\%). The fewest "excellent" responses were recorded for the item "encouraged me to ask questions" (79.2\%) (Table 1).

Cronbach's alpha indicated a high internal consistency $(\alpha=.941)$. Kolmogorov Smirnov analysis was used to assess data normality, which was found to be non-normally distributed $(p<.001)$. Mann-Whitney $\mathrm{U}$ testing found that there was no significant difference between gender and percentage of "excellent" responses $(U=1110.5, p=.60)$, history of osteopathy visits and "excellent" responses $(U=1076, p=.374)$ or two time 
point pain duration and percentage of "excellent" responses $(U=1342, p=.741)$ (Figure 1 and 2). Additionally, Kruskal-Wallis testing found that there was no significant difference between four time point pain duration and percentage of "excellent" responses $(p=.827)$ (Figure 3).

\section{Figure 1}

Mean Percentage of Excellent Responses for Different Patient Demographic

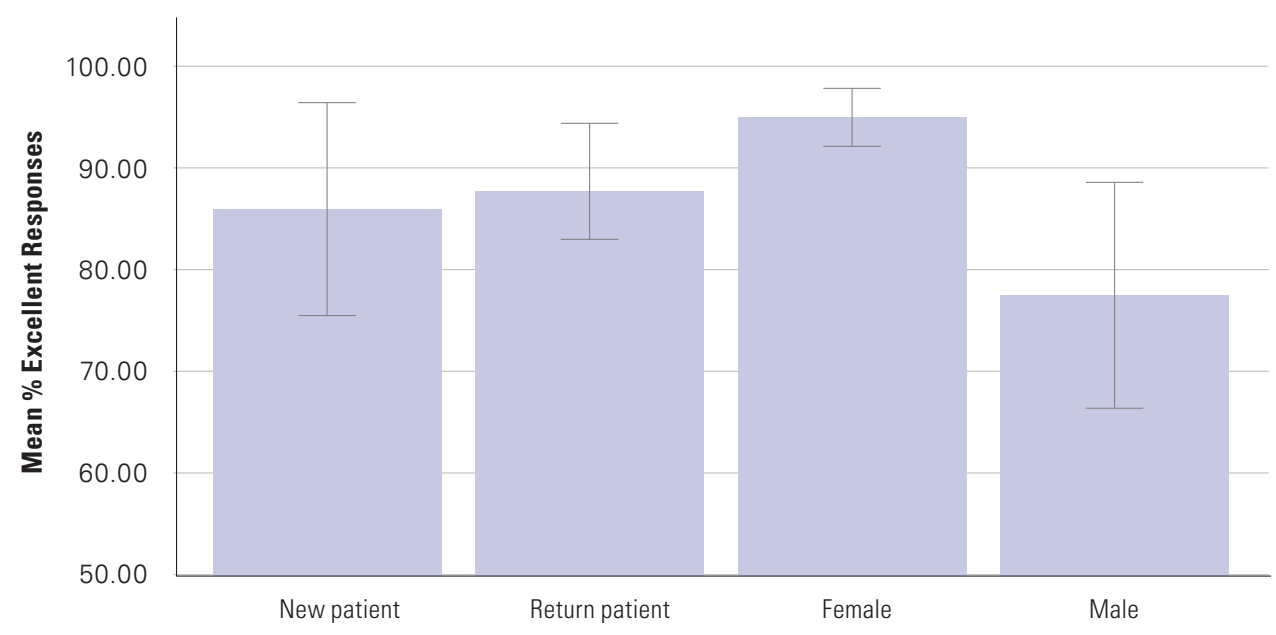

New and Return Patients and Gender

Error bars: $95 \% \mathrm{Cl}$

\section{Figure 2}

Mean Percentage of Excellent Responses for Acute and Chronic Pain Durations

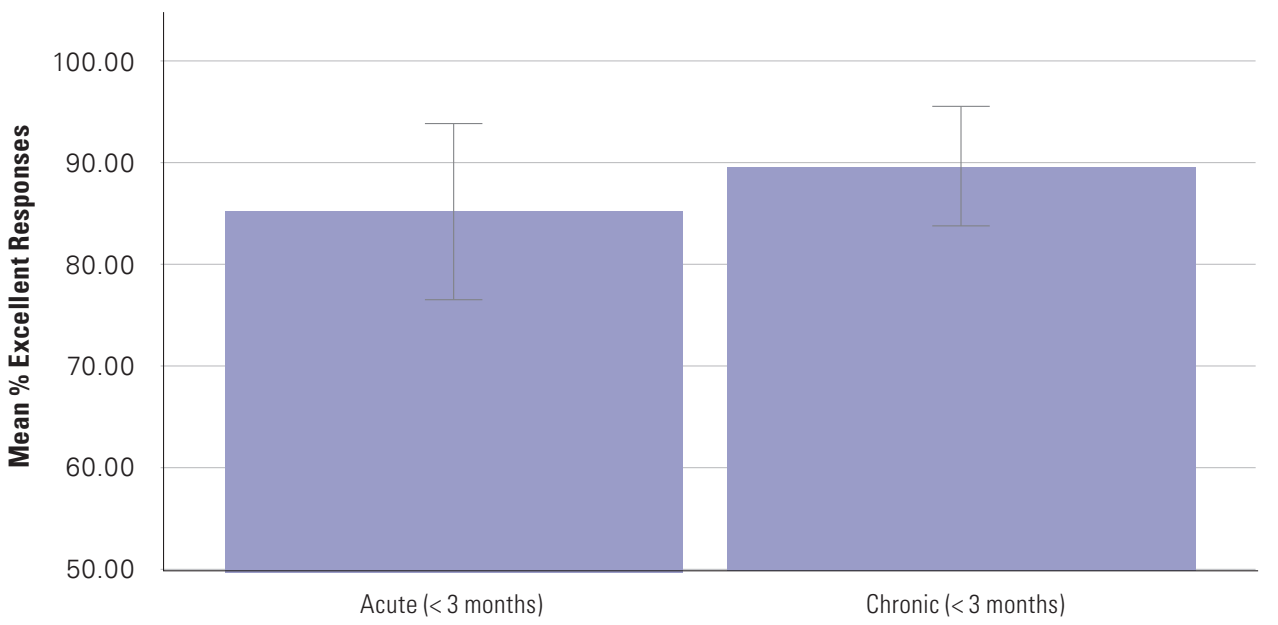

Pain Duration

Error bars: $95 \% \mathrm{Cl}$ 


\section{Figure 3}

Kruskal-Wallis Analysis of Four Point Pain Duration and Mean Percentage of Excellent Responses

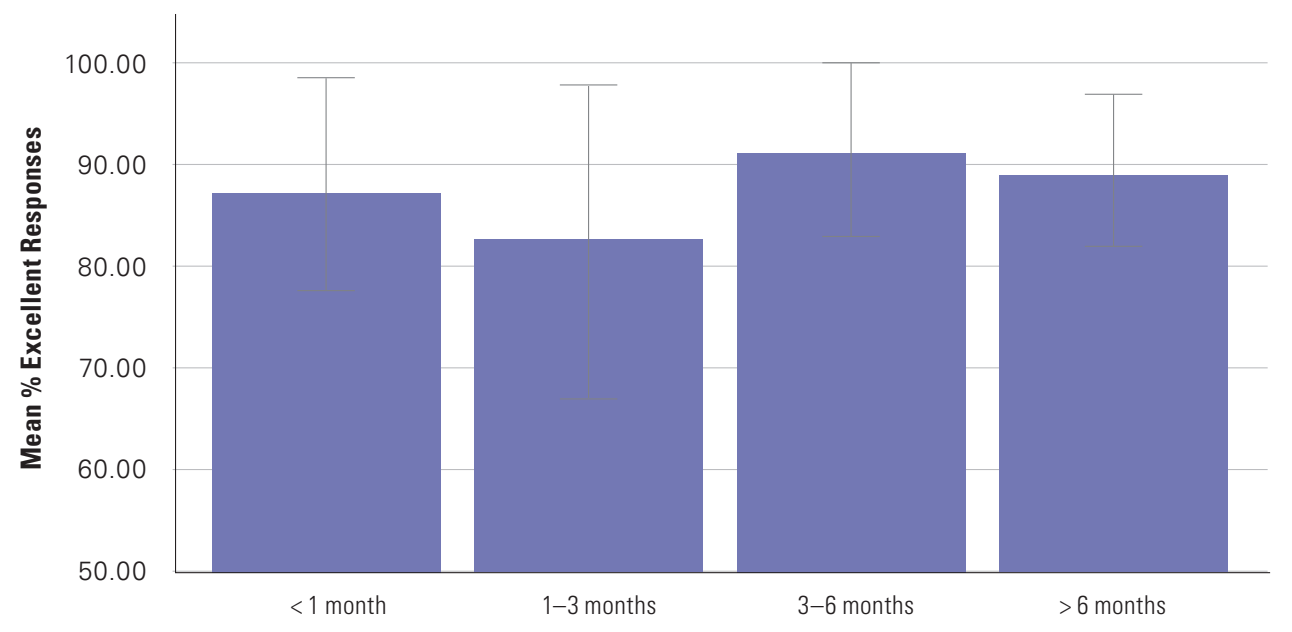

Pain Duration

Error bars: $95 \% \mathrm{Cl}$

\section{Discussion}

It is well known that patient-practitioner interaction and treatment success are interrelated in the clinical setting (Mauksch et al., 2008). More specifically, good communication skills can strengthen the therapeutic relationship and improve the overall quality of care that patients receive, thereby improving health outcomes (Anhang Price et al., 2014; Black et al., 2014). Although considerable research has been devoted to patient perceptions of practitioner communication and interpersonal skills in the hospital and public health systems, there have been fewer attempts to understand these concepts within the allied health fields or within allied health student training clinics. Therefore, this project aimed to investigate the patient-perceived level of communication and interpersonal skills within a university-based osteopathic student teaching clinic.

The overarching results of this study indicate that the majority of participants rated the students' communication and interpersonal skills to be excellent. From this, we can infer that these skills may be contributing positively to patient experience and that the current communication skills component of the curriculum is adequate. This high portion of "excellent" responses, however, may represent a "ceiling effect" that is commonly seen in patient experience outcome measures (Myerholtz et al., 2010), whereby there is a correlation between short, positively framed questionnaires and positive satisfaction scores (Dunsch et al., 2018; Salisbury et al., 2005). Thus, the high percentage of "excellent" responses seen in this research may be attributed to the CAT using exclusively positively framed questions. Using a separate, analogous survey that did not use exclusively 
positively phrased questions or used more in-depth qualitative questioning may have yielded different results to those found in the present study.

The high portion of "excellent" responses found in this research is consistent with previous CAT evaluations in other clinical areas, with work by Myerholtz et al.

(2010), Pestana-Santos et al. (2018) and Makoul et al. (2007) reporting mean patient response scores of 4.59, 4.28 and 4.68, respectively. These results highlight that patients consistently report a high percentage of "excellent" responses despite the varied settings of psychiatry, dermatology, family medicine and physical medicine. Furthermore, in light of our results, it appears patients perceive allied health students to have a similar level of communication skill when compared to fully qualified health professionals (DeBlasio et al., 2019; Makoul et al., 2007; Stausmire et al., 2015; Yu et al., 2018). This should be interpreted with caution, however, as more work is needed to validate the CAT in allied health and student practitioner contexts.

A study by Mercer et al. (2008) found that only 54\% of patients in a high-stress emergency hospital department scored the CAT as "excellent" for "greeted me in a way that made me comfortable" in contrast to our study, which was scored at $91.5 \%$ "excellent". This may be attributed to the difference in atmosphere between settings, as the VU student clinic, with its generous consultation times, provides adequate time for a proper introduction and to fully hear the patient's pain story. Perhaps further time constraints, similar to that in the private practice or hospital setting, may have resulted in a more negative perception of the practitioners' communication and interpersonal skills. That said, work by Myerholtz et al. (2010) suggests that the way in which the time in a consultation is used is most important when analysing communication, rather than the amount of time available. Viewing this through the lens of our current study, the quality of communication and interpersonal skills is seemingly more important than its quantity.

Despite the vast majority of participants scoring the student practitioners as "excellent" in all facets of the CAT, the two lowest scored questions were "checked to be sure I understood everything" and "encouraged me to ask questions," scored at $81.1 \%$ and $79.2 \%$ "excellent", respectively. Despite this score still being relatively high, this highlights potential areas of focus for the communication education of osteopathy students. The commonality between these two questions are that they both require the practitioner to ask for input and understanding from the patient. Given that verbally-expressed patient comprehension is a key pillar of informed consent (O'Toole, 2020), skills in facilitating two-way communication with patients may need to be more strongly emphasised within the curriculum.

Not only is the CAT an effective tool in assessing perceptions of practitioner communication, it may have utility in communication skills education. Muddle et al. (2019) highlight the role that reflection and problem-based learning have in a structured approach to teaching communication skills. This includes self-reflection, role-play and review, and integrating theoretical and practical concepts of effective 
clinical communication to enhance retention of students' skills. Additionally, research recommends utilising the Kirkpatrick model of training to enhance retention and learning of communication skills (Muddle et al., 2019), specifically level two. This level is where reflection occurs, and students change knowledge, skills or attitude based on feedback (Deveugele, 2015). Furthermore, Vogel et al. (2018) recommend assessing and giving feedback on individual components of communication (i.e., verbal and non-verbal communication), as students display different innate and learnt capabilities in each. Building on this, the CAT tool could be purposed as a feedback and reflective practice instrument, by providing a subjective measure of communication and interpersonal skills, both cross-sectionally and longitudinally.

The link between communication and interpersonal skills and patient outcomes appears to be consistent across healthcare settings. Within a physical therapy context, O'Keeffe et al. (2016) found that encouragement helped patients feel that their therapist cared about them, which further motivated them to adhere to their management program. Shared decision making, through good communication, was also important to patients, as it ensured their values and preferences were considered, subsequently improving patient adherence (O'Keeffe et al., 2016). Research by Thomson and Collyer (2017) has also described the influential role that osteopathic practitioners can have with their language utility. They identified the patient-practitioner relationship and the reassurance provided as factors contributing to greater success with care. This literature, in conjunction with our results, demonstrates the strong importance of structured, evidence-based communication and interpersonal skills assessment and training as a way of deeply influencing patient health outcomes.

\section{Limitations and future research}

Like DeBlasio et al. (2019) and Myerholtz et al. (2010), this study found that respondents scored practitioners with a high portion of "excellent" ratings. These findings may have been influenced by social desirability bias (DeBlasio et al., 2019). In an attempt to counter this bias, a locked ballot box was used to deposit completed questionnaires and ensure confidentiality. Selection bias may have also affected the results due to this being a single-centre cohort. There is also the possibility that the "ceiling effect" commonly seen in patient experience outcome measures (Myerholtz et al., 2010) influenced the results of this work. Although every attempt was made to blind the student practitioners to the study, some may have been aware of the data collection period and changed their patient communication strategies accordingly. Furthermore, a small proportion of the participants completed the CAT more than once, however given the consistent results found, we surmise that this did not impact on the results.

Future research could explore the utility of the CAT by administering the questionnaire over multiple time points to monitor trends in communication skills and assess improvement. The CAT could be used in a toolbox that includes self-assessment tools, 
observation, examinations, interactive computer modules or additional surveys that focus on other aspects of communication to ensure high quality evaluation (Makoul et al., 2007). To develop normative data for the CAT responses, future studies should increase the number of participants to improve the generalisability of the results. Further validation of the CAT should also be performed within allied health settings. Prospective research could also use wording techniques, such as positively and negatively phrased questions, to reduce potential response bias (Dunsch et al., 2018; Myerholtz et al., 2010) and, also, utilise qualitative methods to gain a deeper insight into patient perceptions of practitioner communication skills.

\section{Conclusion}

Efficient communication between the patient and practitioner is a critical part of any consultation, as it can enhance overall patient health outcomes. This research sought to understand the patient-perceived rating of student osteopathic clinician communication and interpersonal skills using the CAT. Our results suggest that, overall, patients perceive osteopathic students to have strong communication and interpersonal skills and also demonstrate that encouraging patient questions and facilitating two-way discussions could be improved. Finally, our results reinforce the evidence supporting the generalisability of the CAT across a range of healthcare specialities. These results can be used to inform current and future tertiary allied health communication training. Future research could use the CAT over multiple time points to assess improvements and trends across student and practising health professional cohorts in response to communication and interpersonal pedagogical interventions.

\section{Conflicts of interest and funding}

The authors declare no conflict of interest. This research did not receive any specific grant from funding agencies in the public, commercial or not-for-profit sectors.

\section{References}

Anhang Price, R., Elliott, M. N., Zaslavsky, A. M., Hays, R. D., Lehrman, W. G., Rybowski, L., Edgman-Levitan, S., \& Cleary, P. D. (2014). Examining the role of patient experience surveys in measuring health care quality. Medical Care Research and Review, 71(5), 522-554. https://doi.org/10.1177/1077558714541480

Black, N., Varaganum, M., \& Hutchings, A. (2014). Relationship between patient reported experience (PREMs) and patient reported outcomes (PROMs) in elective surgery. BMJ Quality \& Safety, 23(7), 534-542. https://doi.org/10.1136/ bmjqs-2013-002707 
Boissy, A., Windover, A. K., Bokar, D., Karafa, M., Neuendorf, K., Frankel, R. M., Merlino, J., \& Rothberg, M. B. (2016). Communication skills training for physicians improves patient satisfaction. Journal of General Internal Medicine, 31(7), 755-761. https://doi.org/10.1007/s11606-016-3597-2

Carrigan, N., Rodger, S., \& Copley, J. (2001). Parent satisfaction with a paediatric occupational therapy service: A pilot investigation. Physical and Occupational Therapy in Pediatrics, 21(1), 51-76. https://doi.org/10.1080/J006v21n01 05

DeBlasio, D., Real, F. J., Ollberding, N. J., \& Klein, M. D. (2019). Provision of parent feedback via the Communication Assessment Tool: Does it improve resident communication skills? Academic Pediatrics, 19(2), 152-156. https://doi.org/10.1016/j. acap.2018.06.013

Deveugele, M. (2015). Communication training: Skills and beyond. Patient Education and Counseling, 98(10), 1287-1291. https://doi.org/10.1016/j.pec.2015.08.011

Dunsch, F., Evans, D. K., Macis, M., \& Wang, Q. (2018). Bias in patient satisfaction surveys: A threat to measuring healthcare quality. BMJ Global Health, 3(2), e000694. https://doi.org/10.1136/bmjgh-2017-000694

Hojat, M., DeSantis, J., \& Gonnella, J. S. (2017). Patient perceptions of clinician's empathy: Measurement and psychometrics. Journal of Patient Experience, 4(2), 78-83. https://doi.org/10.1177/2374373517699273

Kingsley, C., \& Patel, S. (2017). Patient-reported outcome measures and patient-reported experience measures. BJA Education, 17(4), 137-144. https://doi.org/10.1093/bjaed/ $\underline{\mathrm{mkw} 060}$

Kourkouta, L., \& Papathanasiou, I. V. (2014). Communication in nursing practice. Mater Sociomed, 26(1), 65-67. https://doi.org/10.5455/msm.2014.26.65-67

Leach, C. J., Mandy, A., Hankins, M., Bottomley, L. M., Cross, V., Fawkes, C. A., Fiske, A., \& Moore, A. P. (2013). Patients' expectations of private osteopathic care in the UK: A national survey of patients. BMC Complementary and Alternative Medicine, 13(1), Article 122. https://doi.org/10.1186/1472-6882-13-122

Makoul, G., Krupat, E., \& Chang, C.-H. (2007). Measuring patient views of physician communication skills: Development and testing of the Communication Assessment Tool. Patient Education and Counseling, 67(3), 333-342. https://doi.org/10.1016/j. pec.2007.05.005 
Mauksch, L. B., Dugdale, D. C., Dodson, S., \& Epstein, R. (2008). Relationship, communication, and efficiency in the medical encounter: Creating a clinical model from a literature review. Archives of Internal Medicine, 168(13), 1387-1395. https:// doi.org/10.1001/archinte.168.13.1387

Mercer, L. M., Tanabe, P., Pang, P. S., Gisondi, M. A., Courtney, D. M., Engel, K. G., Donlan, S. M., Adams, J. G., \& Makoul, G. (2008). Patient perspectives on communication with the medical team: Pilot study using the Communication Assessment Tool-Team (CAT-T). Patient Education and Counseling, 73(2), 220-223. https://doi.org/10.1016/j.pec.2008.07.003

Muddle, L., O’Malley, C. J., \& Stupans, I. (2019). Learning and teaching of patientcentred communication skills in allied healthcare manual therapy students: A systematic review. International Journal of Osteopathic Medicine, 32, 21-27. https:// doi.org/10.1016/j.ijosm.2019.04.002

Myerholtz, L., Simons, L., Felix, S., Nguyen, T., Brennan, J., Rivera-Tovar, A., Martin, P., Hepworth, J., \& Makoul, G. (2010). Using the communication assessment tool in family medicine residency programs. Family Medicine, 42(8), 567-573. https://fammedarchives.blob.core.windows.net/imagesandpdfs/pdfs/ FamilyMedicineVol42Issue8Myerholtz567.pdf

O’Keeffe, M., Cullinane, P., Hurley, J., Leahy, I., Bunzli, S., O’Sullivan, P. B., \& O'Sullivan, K. (2016). What influences patient-therapist interactions in musculoskeletal physical therapy? Qualitative systematic review and meta-synthesis. Physical Therapy, 96(5), 609-622. https://doi.org/10.2522/ptj.20150240

O’Toole, G. (2020). Communication-eBook: Core interpersonal skills for healthcare professionals. Elsevier Health Sciences.

Osteopathy Australia. (2018). Statement of scope of practice in osteopathy. http://www. theosteopath.net.au/wp-content/uploads/2019/08/data_Scope_of_practice_in_ Osteopathy_2018_FINAL-1.pdf

Pestana-Santos, A., Loureiro, L., Santos, V., \& Carvalho, I. (2018). Patients with schizophrenia assessing psychiatrists' communication skills. Psychiatry Research, 269, 13-20. https://doi.org/10.1016/j.psychres.2018.08.040

Pinto, R. Z., Ferreira, M. L., Oliveira, V. C., Franco, M. R., Adams, R., Maher, C. G., \& Ferreira, P. H. (2012). Patient-centred communication is associated with positive therapeutic alliance: A systematic review. Journal of Physiotherapy, 58(2), 77-87. https://doi.org/10.1016/S1836-9553(12)70087-5 
Salisbury, C., Burgess, A., Lattimer, V., Heaney, D., Walker, J., Turnbull, J., \& Smith, H. (2005). Developing a standard short questionnaire for the assessment of patient satisfaction with out-of-hours primary care. Family Practice, 22(5), 560-569. https:// doi.org/10.1093/fampra/cmi050

Stausmire, J. M., Cashen, C. P., Myerholtz, L., \& Buderer, N. (2015). Measuring general surgery residents' communication skills from the patient's perspective using the Communication Assessment Tool (CAT). Journal of Surgical Education, 72(1), 108-116. https://doi.org/10.1016/j.jsurg.2014.06.021

Street, R. L., Makoul, G., Arora, N. K., \& Epstein, R. M. (2009). How does communication heal? Pathways linking clinician-patient communication to health outcomes. Patient Education and Counseling, 74(3), 295-301. https://doi. org/10.1016/j.pec.2008.11.015

Thomson, O. P., \& Collyer, K. (2017). “Talking a different language”: A qualitative study of chronic low back pain patients' interpretation of the language used by student osteopaths. International Journal of Osteopathic Medicine, 24, 3-11. https://doi. org/10.1016/j.ijosm.2016.11.002

Vaughan, B., Burns, C., Burridge, L., Wigger, J., Blair, S., \& Mulcahy, J. (2019). Patient satisfaction and perception of treatment in a student-led osteopathy teaching clinic: Evaluating questionnaire dimensionality and internal structure, and outcomes. International Journal of Osteopathic Medicine, 31, 21-27. https://doi.org/10.1016/j. ijosm.2019.01.002

Vermeir, P., Vandijck, D., Degroote, S., Peleman, R., Verhaeghe, R., Mortier, E., Hallaert, G., Van Daele, S., Buylaert, W., \& Vogelaers, D. (2015). Communication in healthcare: A narrative review of the literature and practical recommendations. International Journal of Clinical Practice, 69(11), 1257-1267. https://doi.org/10.1111/ ijcp.12686

Vogel, D., Meyer, M., \& Harendza, S. (2018). Verbal and non-verbal communication skills including empathy during history taking of undergraduate medical students. BMC Medical Education, 18(1), 1-7. https://doi.org/10.1186/s12909-018-1260-9

Yu, M. X., Jiang, X. Y., Li, Y. J., Shen, Z. Y., Zhuang, S. Q., \& Gu, Y. F. (2018). Evaluation of medical record quality and communication skills among pediatric interns after standardized parent training history-taking in China. Medical Teacher, 40(2), 188-192. https://doi.org/10.1080/0142159X.2017.1395833 